\title{
Erratum to: Intra-specific variation in nitrate tolerance in tadpoles of the Natterjack toad
}

\author{
Claude Miaud · Neus Oromí • Sandra Guerrero • \\ Delfí Sanuy
}

Published online: 1 June 2011

(C) Springer Science+Business Media, LLC 2011

Erratum to: Ecotoxicology

DOI 10.1007/s10646-011-0662-9

The co-author's (Dr. Sandra Guerrero) name was published incorrectly in the original publication of the article. The author's name should read Sandra Guerrero.

The online version of the original article can be found under doi:10.1007/s10646-011-0662-9.

C. Miaud $(\bowtie) \cdot$ S. Guerrero

Laboratory of Alpine Ecology, University of Savoie,

UMR CNRS 5553, Le Bourget du Lac, France

e-mail: claude.miaud@univ-savoie.fr

N. Oromí · D. Sanuy

Department of Animal Production (Wild Animals),

University of Lleida, Lleida, Catalonia, Spain 